\title{
ZONING OF AREAS WITH SUSCEPTIBILITY TO OAK DECLINE IN WESTERN IRAN
}

\author{
Mohadeseh Ghanbari Motlagh @ ${ }^{1}$, Masoud Kiadaliri ${ }^{2}{ }^{2}$ \\ ${ }^{1}$ Islamic Azad University, Tehran, Iran \\ ${ }^{2}$ Islamic Azad University, Tonekabon, Iran \\ Manuscript received: November 22, 2020 \\ Revised version: January 27, 2021
}

\begin{abstract}
Ghanbari Motlagh M., Kiadaliri M., 2021. Zoning of areas with susceptibility to oak decline in western Iran. Quaestiones Geographicae 40(1), Bogucki Wydawnictwo Naukowe, Poznań, pp. 75-83. 1 table, 3 figs.

AвSTRACT: Zagros forests have the greatest impact on soil and water protection in western Iran. Despite this, a significant part of these forests, especially in Ilam province, have suffered a lot due to the phenomenon of oak decline. The first and most fundamental thing a person must know when combating this issue is the distribution of these areas in forests. Therefore, using the parameters affecting the decline in the forests of Ilam province and based on fuzzy logic, a map of susceptible to oak decline areas was prepared. In this study, the parameters of temperature and precipitation, slope, aspect, altitude, distance from farmlands, roads and forest density were selected as effective parameters and fuzzy gamma overlap method was used. The results showed that more than $77 \%$ of the oak forests in the province are highly and extremely susceptible to the decline. This confirms the need for rapid action to plan and protect these forests. In addition, the fuzzy method is proposed, which is considered as a fast and efficient method in preparing such maps for other areas.
\end{abstract}

KEY WORDS: decline, fuzzy gamma, Ilam, mapping

Corresponding author: Mohadeseh Ghanbari Motlagh; mohadeseh.motlagh@gmail.com

\section{Introduction}

In recent years, large-scale mortality and drought have occurred in the Zagros forests of western Iran, degrading thousands of oak trees (Zandebasiri et al. 2017, 2019, Hosseini et al. 2019, Ghanbari Motlagh et al. 2020, Jahanbazi Gojani et al. 2020). This phenomenon has been reported first time in the 2000s, especially in the forests of Ilam province, which has caused concern among foresters and authorities (Amir Ahmadi et al. 2015, Attarod et al. 2017, Kooh Soltani et al. 2018, Alesheikh and Mehri 2019, Mozafari et al. 2019). This is important because the forests of the Zagros cover $40 \%$ of the total forests of Iran, with an area of more than 5 million hectares (Ghadirian et al. 2018, Goodarzi et al. 2019, Zandebasiri et al. 2019).

Different species of Zagros oak including Quercus brantii Lindl., Quercus infectoria and Quercus libani are the most important and extensive forest ecosystems in Iran (Hosseini et al. 2017, 2019, Alesheikh and Mehri 2019, Mozafari et al. 2019). In addition, they play a very important role in water supply, soil protection, ecological balance and socio-economic status of residents (Costa et al. 2010, Ahmadi et al. 2014, Zandebasiri et al. 2019). Decline in tree species, especially oaks, is a function of various environmental parameters (Jurskis 2005, Gonzalez Alonso, Johansson

\section{sciendo}


2008). These factors include droughts and climate change, reduced soil fertility, land use changes, pests and diseases, livestock grazing, etc., which have affected the health of trees and caused the phenomenon of decline globally (Oszako 2004, Eckhardt, Menard 2008, Gonzalez Alonso et al. 2008, Greenwood and Weisberg 2008, Kabrick et al. 2008, Costa et al. 2010, Ahmadi et al. 2014, Sohar et al. 2014, Keča et al. 2016, Amir Ahmadi et al. 2015, Attarod et al. 2017, Hosseini et al. 2017, Zandebasiri et al. 2017, 2019, Ghadirian et al. 2018, Alesheikh, Mehri 2019, Conte et al. 2019, Goodarzi et al. 2019, Mozafari et al. 2019, Touhami et al. 2019). Therefore, it is necessary to provide an appropriate model by considering these factors in order to prioritise declining forest areas to support decision-making by identifying susceptible areas and introducing preventive operations (Ghadirian et al. 2018, Kooh Soltani et al. 2018, Goodarzi et al. 2019, Mozafari et al. 2019). The decay of these forests has many irreversible ecological and socio-economic consequences for the future of the region (Kooh Soltani et al. 2018, Ghanbari Motlagh et al. 2020).

Today, with the development of new technologies and different patterns in zoning, some researches in this field would have been performed using different methods (Goodarzi et al. 2019). The most widely used among the methods are logistic regression models (Mahdavi et al. 2015a, Ghadirian et al. 2018), neural network models (Alesheikh, Mehri, 2019) and multi-criteria evaluation methods (Ahmadi et al. 2014, Kooh Soltani et al. 2018, Ghanbari Motlagh et al. 2020) in order to construct zoning maps of decline/dieback potential and determine the effective criteria. One of these methods is fuzzy logic, which has helped to solve many decision-making problems nowadays, and in most cases, it produces the best decision based on input data (Mohebbi Tafreshi et al. 2019). Fuzzy logic was first used by Professor Lotfi Asgarzadeh in 1965 to mean inaccurate, vague and ambiguous. In fuzzy logic, the degree of certainty or accuracy of a statement is expressed by a number between 0 and 1 . Unlike Boolean or digital logic, the correctness of any statement is determined by two values, True and False (Zadeh 1965). Fuzzy is the spectrum between black and white, which allows modelling for real-world uncertain situations (Zadeh 1965). Fuzzy logic is one of the standard methods for selecting a suitable location and is basically a method of weighting the layers used because generally the parameters in the site selection are largely fuzzy in nature. This method is one of the most acceptable location methods (Lee 2007, Lewis et al. 2014, Mohebbi Tafreshi et al. 2019). Therefore, in this study, we used it to prepare a decline susceptibility map in the oak forests of Zagros in Ilam province in western Iran.

\section{Material and methods}

\section{Study area}

Ilam Province have an area about 20,13,284 square kilometres and is located between $32^{\circ}$ to $34^{\circ} \mathrm{N}$ latitude and $45^{\circ}$ to $48^{\circ} \mathrm{E}$ longitudes. The minimum altitude is $28 \mathrm{~m}$ and the maximum is $2783 \mathrm{~m}$ above sea level. It is bounded by Kermanshah province from the north, Khuzestan from the south, Lorestan from the east and Iraq from the west (Fig. 1). The climate of province is semi-humid Mediterranean and the soils of the region are in the category of shallow to semi-deep gravelly soils (Mahdavi et al. 2015b). This province has about 600,000 hectares of forest, which is one of the semi-arid forests of the Zagros, and its predominant type is Persian oak (Q. brantii), which has about $90 \%$ of the province's forest cover, which unfortunately, according to reports of Department of Natural Resources and Watershed Management of Ilam Province Large parts of the Zagros forests of this province have been affected by oak decline in recent years (Ilam Department 2013).

\section{Study method based on fuzzy logic model}

In this research, at first, internal and external reports, statistics and information and articles related to the issue of decline in the province were studied and based on 10 parameters affecting the phenomenon of forest decline in this province, a database was prepared in geographic information system (GIS) environment. Selected parameters for mapping of areas with susceptibility to decline are altitude, slope, aspect, forest density, distance from roads, distance from farmlands and distance from streams, total annual precipitation, and average annual temperature (Table 1). 
In order to prepare slope and aspect maps, digital elevation model (DEM) was used. Information of 8 synoptic stations of the province was used to prepare climate maps of total annual precipitation $(\mathrm{mm})$ and mean annual temperature $\left({ }^{\circ} \mathrm{C}\right)$ (Ghadirian et al. 2018). In order to

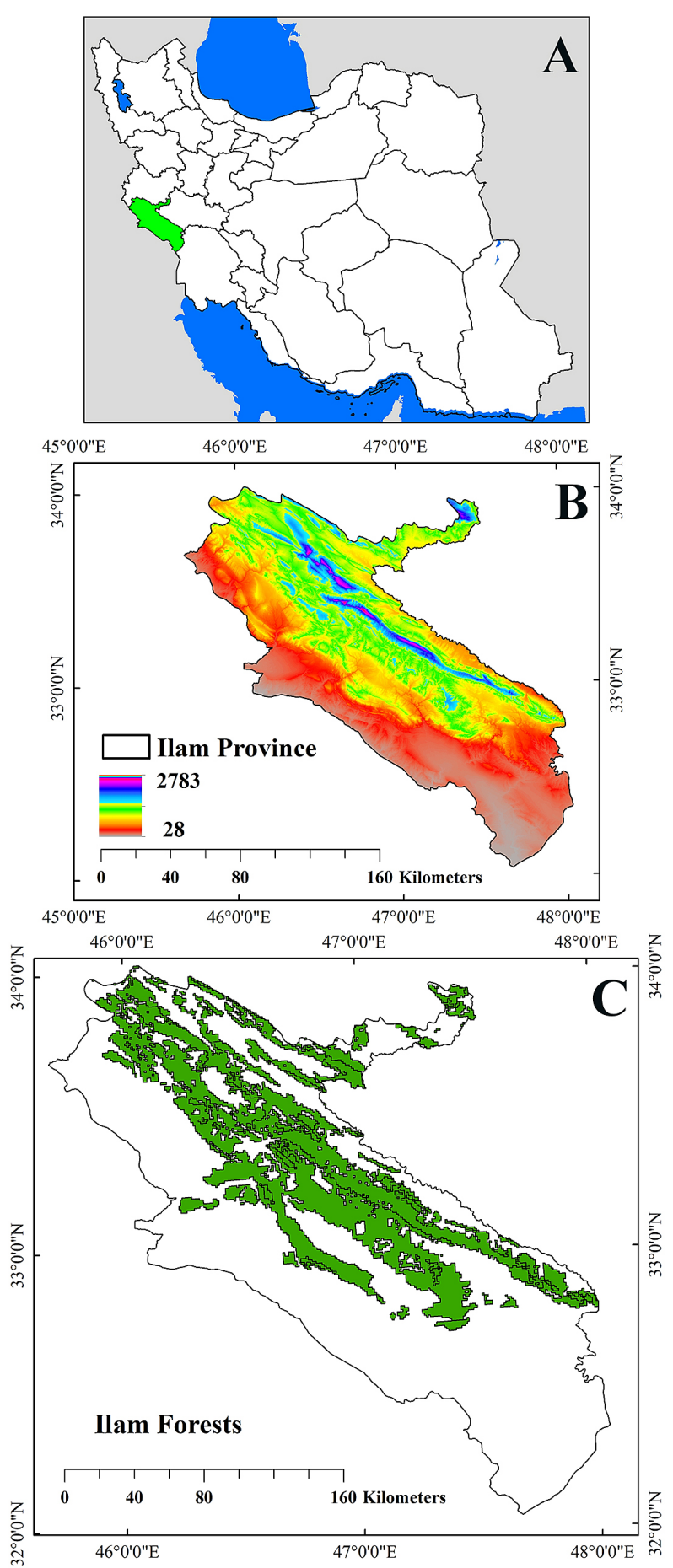

Fig. 1. Geographical location of Ilam province in Iran (A), digital elevation model of Ilam province (B) and its forests $(\mathrm{C})$. extract the layer of roads, streams and farmlands, the topographic map of the region including roads, streams and farming lands of the province was used. To achieve this purpose and to create a raster map of these parameters, the 'Distance' option was used to calculate the Euclidean distance of the parameters in ArcGIS software. Finally, the forest density map of the province was made from the maps prepared based on the statistics conducted by the Department of Natural Resources and Watershed Management of Ilam province (Ilam Department 2013).

The scale of the prepared basic maps of parameters is different. In the subsequent step, fuzzy sets are defined for these parameters, in which each pixel, takes on different degree of membership depending on the distance from the feature. To match the scale of the maps and convert them to comparable units, the fuzzy process ( 0 to 1$)$ based on fuzzy logic and the definition of appropriate membership functions was used. In fact, in fuzzy logic, the membership of an element in a set is defined by a value in the range of 1 (full membership) to 0 (no full membership). Membership rank is usually expressed by a membership function. In fact, in order to fuzzy the parameter map, it is necessary to determine the type of membership function (Raines et al. 2010). There are several types of membership functions such as Gaussian, Small, Large, Near, MS Small, MS Large and Linear membership functions that are used for fuzzification (Raines et al. 2010, Mohebbi Tafreshi et al. 2019).

Further, fuzzy logic and definition of the appropriate membership functions were used using the 'Fuzzy membership' option in ArcGIS software for fuzzification all digital raster maps of the study parameters (Raines et al. 2010) (Table 1). After all the parameters are fuzzified by the fuzzy membership method and the pixel values are converted to numbers between 0 and 1 , it is necessary to overlap these parameters. Suitable fuzzy operators and Fuzzy Overlay option in ArcGIS software were used to combine the parameters. Finally, by applying fuzzy operators to the pixel units, the output map will contain the degree of membership (Raines et al. 2010). Among overlapping operators, the use of the gamma operator is more common than other operators (Lewis et al. 2014, Mohebbi Tafreshi et al. 2019). This operator is a general case of fuzzy 
Table 1. Parameters affecting the decline of oak forests in Ilam province, information source and fuzzy membership function.

\begin{tabular}{|c|c|c|c|c|}
\hline No. & Parameters & Information source & $\begin{array}{l}\text { Fuzzy member- } \\
\text { ship function } \\
\text { type }\end{array}$ & References \\
\hline 1 & Slop [\%] & DEM ASTER & Linear & $\begin{array}{l}\text { Eckhardt and Menard 2008, Kabrick et al. 2008, } \\
\text { Costa et al. 2010, Ahmadi et al. 2014, Amir } \\
\text { Ahmadi et al. 2015, Mahdavi et al. 2015a, Hos- } \\
\text { seini et al. 2017, Ghadirian et al. 2018, Kooh } \\
\text { Soltani et al. 2018, Mozafari et al. } 2019\end{array}$ \\
\hline 2 & Aspect $\left[{ }^{\circ}\right]$ & DEM ASTER & Near & $\begin{array}{l}\text { Eckhardt and Menard 2008, Kabrick et al. 2008, } \\
\text { Costa et al. 2010, Ahmadi et al. 2014, Amir } \\
\text { Ahmadi et al. 2015, Mahdavi et al. 2015a, Hos- } \\
\text { seini et al. 2017, Ghadirian et al. 2018, Kooh } \\
\text { Soltani et al. 2018, Mozafari et al. } 2019\end{array}$ \\
\hline 3 & Altitude [m asl] & DEM ASTER & Small & $\begin{array}{l}\text { Eckhardt and Menard 2008, Kabrick et al. 2008, } \\
\text { Costa et al. 2010, Ahmadi et al. 2014, Amir } \\
\text { Ahmadi et al. 2015, Mahdavi et al. 2015a, Hos- } \\
\text { seini et al. 2017, Ghadirian et al. 2018, Kooh } \\
\text { Soltani et al. 2018, Mozafari et al. } 2019\end{array}$ \\
\hline 4 & $\begin{array}{l}\text { Precipitation } \\
{[\mathrm{mm}]}\end{array}$ & $\begin{array}{l}\text { Information of synoptic } \\
\text { stations of Meteorologi- } \\
\text { cal Organization of Iran, } \\
\text { Kriging interpolation } \\
\text { model in GIS }\end{array}$ & Small & $\begin{array}{l}\text { Eckhardt and Menard 2008, Kabrick et al. 2008, } \\
\text { Costa et al. 2010, Ahmadi et al. 2014, Amir Ah- } \\
\text { madi et al. 2015, Mahdavi et al. 2015a, Attarod } \\
\text { et al. 2017, Hosseini et al. 2017, Ghadirian et al. } \\
\text { 2018, Kooh Soltani et al. 2018, Conte et al. 2019, } \\
\text { Mozafari et al. } 2019\end{array}$ \\
\hline 5 & $\begin{array}{l}\text { Temperature } \\
{\left[{ }^{\circ} \mathrm{C}\right]}\end{array}$ & $\begin{array}{l}\text { Information of synoptic } \\
\text { stations of Meteorologi- } \\
\text { cal Organization of Iran, } \\
\text { Kriging interpolation } \\
\text { model in GIS }\end{array}$ & Linear & $\begin{array}{l}\text { Ahmadi et al. 2014, Mahdavi et al. 2015a, At- } \\
\text { tarod et al. 2017, Hosseini et al. 2017, Ghadi- } \\
\text { rian et al. 2018, Kooh Soltani et al. 2018, Conte } \\
\text { et al. } 2019\end{array}$ \\
\hline 6 & $\begin{array}{l}\text { Distance from } \\
\text { streams }[\mathrm{m}]\end{array}$ & $\begin{array}{l}\text { Surface water layer of } \\
\text { Iran Water Resources } \\
\text { Management Company }\end{array}$ & Linear & Ghadirian et al. 2018 \\
\hline 7 & $\begin{array}{l}\text { Distance from } \\
\text { roads }[\mathrm{m}]\end{array}$ & $\begin{array}{l}\text { Iran National Car- } \\
\text { tographic Center }\end{array}$ & Linear & Ghadirian et al. 2018 \\
\hline 8 & $\begin{array}{l}\text { Distance from } \\
\text { farming lands } \\
{[\mathrm{m}]}\end{array}$ & $\begin{array}{l}\text { Iran National Car- } \\
\text { tographic Center }\end{array}$ & Linear & Ghadirian et al. 2018 \\
\hline 9 & Forest density & $\begin{array}{l}\text { Department of Natural } \\
\text { Resources and Water- } \\
\text { shed Management of } \\
\text { Ilam Province }\end{array}$ & Linear & $\begin{array}{l}\text { Mahdavi et al. 2015a, Ghadirian et al. 2018, } \\
\text { Conte et al. } 2019\end{array}$ \\
\hline
\end{tabular}

multiplication and sum operators and is obtained using the following equation.

Correct and conscious choice of $\gamma$ between 0 and 1 by the user creates values in the output that indicate a flexible compatibility between the decreasing and increasing tendencies of the two operators of sum and multiplication fuzzy. The gamma operator is a combination of sum and multiplication fuzzy operators in which gamma value is between 0 and 1 . When the gamma is 0 , this operator is the same as the fuzzy multiplication operator, and when the gamma is equal to 1 , this operator will be equal to the fuzzy sum operator. This parameter determines how the actual behaviour of the operator changes between the AND and fuzzy OR situation (Lee 2007, Lewis et al. 2014, Mohebbi Tafreshi et al. 2019).

In order to prepare the final map of susceptible areas, the standardised map of decline parameters was overlapped using fuzzy gamma operator (gamma 0.9). The map prepared by classification was classified into four classes of decline (low, medium, high and severe decline). The areas with high and severe decline susceptibility points were randomly identified and field visits were done to confirm the accuracy of the obtained map. 


\section{Results}

Standardised maps of the parameters were made based on the fuzzy functions defined in Table 1 (Fig. 2) and the final map of areas with susceptibility to oak decline was prepared (Fig. 3).

The present study has shown that all forests in the province are susceptible to decline. It is observed that $58.39 \%$ have severe susceptibility to decline, $19.85 \%$ have high susceptibility to decline, $16.71 \%$ have moderate susceptibility to decline and only about $6 \%$ have low susceptibility to decline.

\section{Discussion}

A wide range of Zagros oak forests in Iran, especially in Ilam province, has suffered from susceptibility to oak decline and even ecosystem decline over the past decade. In this study, an attempt has been made to provide a zoning map of susceptibility to oak decline in this province based on a number of ecological, biological and socio-economic parameters using a fuzzy method based on GIS.

Oak decline is a phenomenon involving a set of factors that affect susceptible trees (Oszako

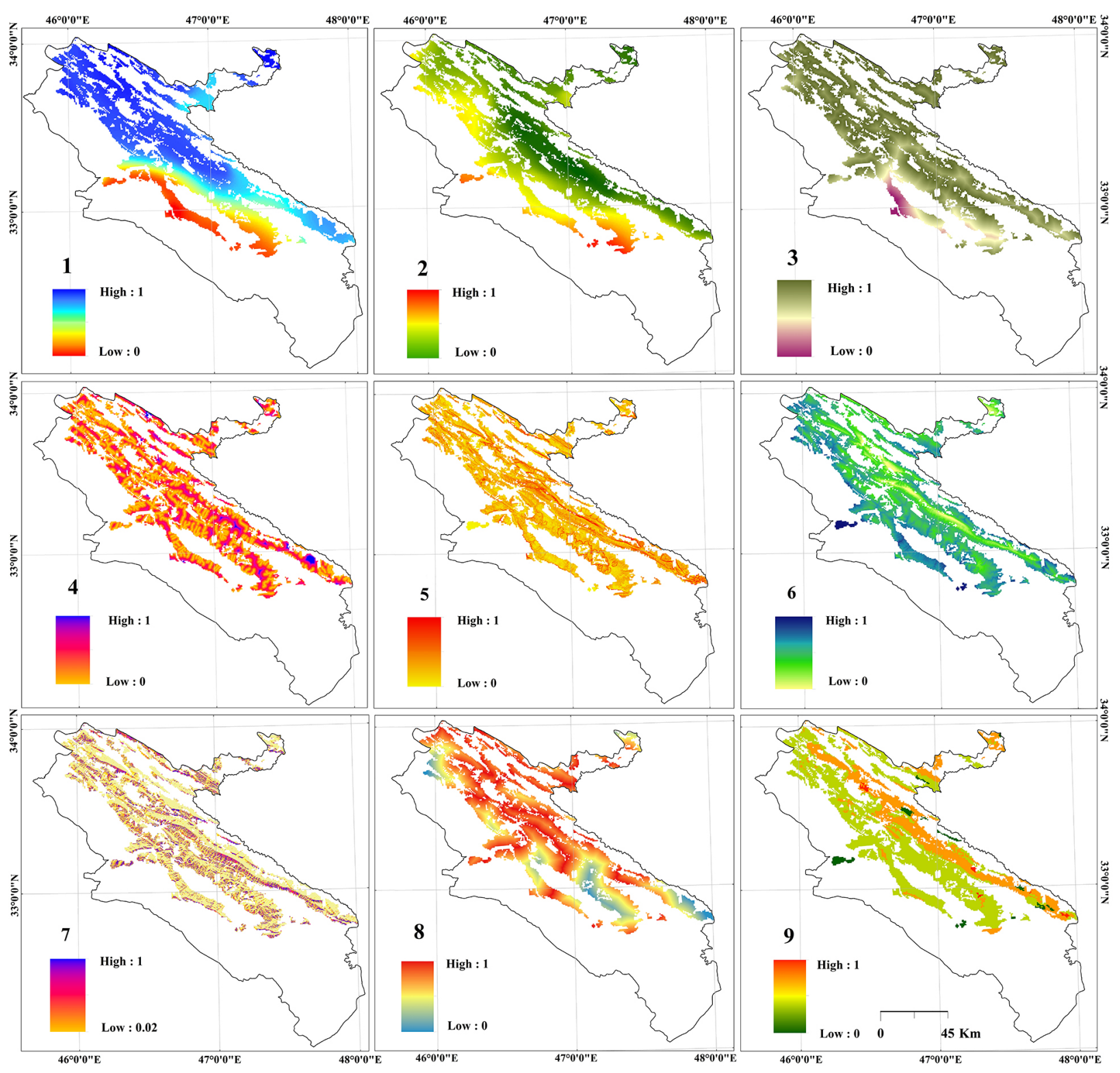

Fig. 2. Standardised maps of effective parameters in oak decline.

1 - precipitation, 2 - temperature, 3 - distance from farmland, 4 - distance from streams, 5 - slopes, 6 - altitude, 7 aspect, 8 - distance from roads, 9 - forest density. 


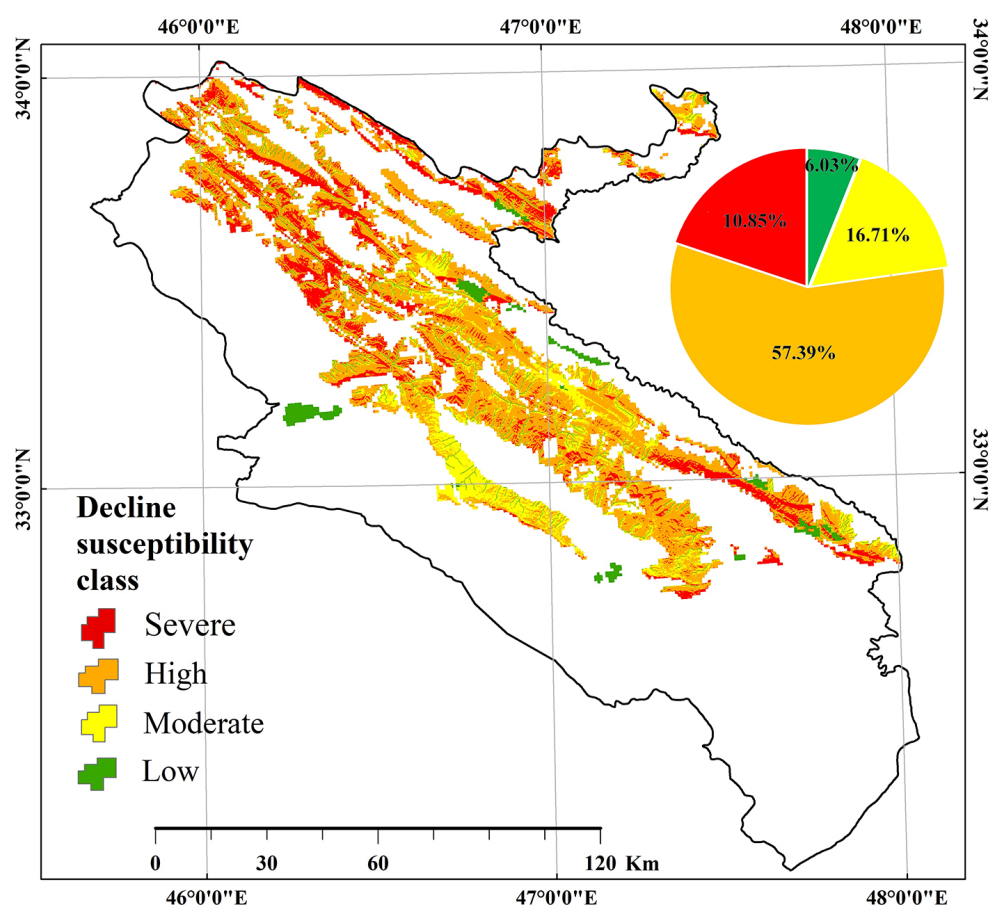

Fig. 3. Final map of areas with susceptibility to oak in Ilam forests and classification area.

2004). Tree mortality reduces the quantity and quality of forest stands and negatively affects the performance of forest ecosystems. On the other hand, low species diversity in the context of these unfavourable conditions, beside events such as drought, cause deforestation (Keča et al. 2016). As a result, the regression process is accelerated and its structural changes are fully visible (Hamzehpour et al. 2011, Rostamnia and Akhoondzadeh Hanzaei 2016, Attarod et al. 2017, Jahanbazi Gojani et al. 2020). This issue has been mentioned in most studies related to the mortality of forest trees, especially oak species are very sensitive, worldwide (Jurskis 2005, Eckhardt and Menard 2008, Gonzalez Alonso, Johansson 2008, Costa et al. 2010, Sohar et al. 2014, Conte et al. 2019, Touhami et al. 2019).

The final map created is close to the fuzzy map of climatic factors. Especially areas with low rainfall indicate higher drought stress, because when rainfall decreases, evapotranspiration increases, and the possibility of weakening against stressors such as diseases, fungi and insects, which increase the possibility of decline (Eckhardt and Menard 2008, Kabrick et al. 2008, Sohar et al. 2014, Attarod et al. 2017, Hosseini et al. 2017, Pourhashemi et al. 2017, Conte et al. 2019, Goodarzi et al. 2019, Mozafari et al. 2019, Touhami et al. 2019).
Studies of Rostamnia et al., Akhoondzadeh Hanzaei (2016) and Hosseini et al. (2017) have shown that this province has been facing drought and rainfall changes in recent years, and especially oak species are very sensitive in response to these droughts. Data and a large number of trees have suffered from decline or physiological weakness and have been destroyed directly by drought or indirectly by pest outbreaks. Also studies of Hamzehpour et al. (2011), Ahmadi et al. (2014), Mahdavi et al. (2015a), Attarod et al. (2017), Goodarzi et al. (2019) and Mozafari et al. (2019) have revealed the relationship between climatic factors and oak mortality in the Zagros region.

Generally, weather conditions like high precipitation, low temperature, high farming land and low distance from streams favour the development of alien invasive oomycetes, especially Phytophthora genus (Woodward et al. 2005). Zoospores released, for example, after heavy rains can easily infect fine roots and interact with pathogenic fungi like Armillaria spp., which cause direct mortality of trees (Nowakowska et al. 2020). In such condition, the decline of trees becomes more severe when drought occurs after wet years. Damaged roots are not efficient in absorbing of water from dry soil. Climatic changes can even trigger this phenomenon in the future (Oszako et al. 2016). 
Conversion of forest lands into agricultural lands in the vicinity of these forests in many areas of the Zagros basin leads to various problems. This allows more access and destruction of forests, soil erosion and even fires (Hamzehpour et al. 2011, Pourhashemi et al. 2017, Zandebasiri et al. 2017, 2019). As can be seen in the final map, the areas with proximity of agricultural land or greater access to roads is seen a higher potential for decline. In Mediterranean countries, the problem of changing the land use has affected the decline of oaks (Quercus suber) (Costa et al. 2010). Eucalyptus forests in Australia have also experienced decline due to human activities such as grazing and changes in forest land use (Jurskis 2005).

Among the topographic parameters, the highest compliance occurs in the elevation map. With increasing altitude and decreasing temperature and lack of access, the rate of deterioration increases (Eckhardt, Menard 2008, Greenwood, Weisberg 2008, Mahdavi et al. 2015a, Mozafari et al. 2019). Slope and aspect parameters act more locally and in many studies they are known as parameters affecting the decline of oaks in the forests of Zagros and the world (Eckhardt and Menard 2008, Ahmadi et al. 2014, Amir Ahmadi et al. 2015, Hosseini et al. 2017). Most mortality occurs in warmer, drier aspects (south and west) and steeper slopes. In these areas, more drought stress, less access to moisture and less soil depth cause trees to dry out and die (Eckhardt, and Menard 2008, Kabrick et al. 2008, Mahdavi et al. 2015a, Hosseini et al. 2017, Mozafari et al. 2019).

The phenomenon of oak decline has occurred in a large area of these forests where environmental parameters and habitat conditions such as climatic factors, topography, apart from socio-economic problems, are at the macro level. But at the local level and on a smaller scale, they have strengths and weaknesses and the appearance of the phenomenon of decline cannot be expected to be the same in different regions (Hamzehpour et al. 2011, Ahmadi et al. 2014, Jahanbazi Gojani et al. 2020).

In the final map of susceptibility to oak decline, which is made based on fuzzy gamma 0.9 , more than $77 \%$ of the province's forests have high and severe susceptibility to decline. But the study Kooh Soltani et al. (2018) in Lorestan province showed that the fuzzy operator had the highest accuracy with $70 \%$ accuracy. This map is compared to the map of decline risk with three class presented based on the AHP (Analytical Hierarchy Process) method by Ahmadi et al. (2014) in which 51.7\% of the area, $36.70 \%$ and $8.28 \%$ are at medium risk, and low respectively, it shows the conditions is much more critical. This situation indicates the need for emergency operations. The results of this study showed that GIS-based fuzzy logic can have great potential in solving complex spatial problems due to its speed, simplicity, and ability to provide acceptable results (Lee 2007, Lewis et al. 2014, Mohebbi Tafreshi et al. 2019) especially in the field of oak decline studies. Such zonings, which are prepared in very simple ways, can be used in the management of all forests in the Zagros region that are facing this problem and can be a guide for decision makers. But it must be considered that the mechanism and manner of relationship of environmental parameters is complex and nonlinear.

\section{Acknowledgments}

We are grateful to all experts in Ilam Department of Natural Resources and Watershed Management for their help with data analysis and gathering information. Also thanking to the reviewers and the editors for their comments and suggestions.

\section{Funding information}

No funding has been received for this research.

\section{Authors' contribution}

Mohadeseh Ghanbari Motlagh has participated in designing and conceptualization the subject of the study, major contributor in writing the manuscript and performing models, preparating figures and models. Masoud Kiadaliri has been involved in gathering information, searching for resources, reviewing the article and editing it. Both the authors read and approved the final manuscript.

\section{References}

Ahmadi R., Kiadaliri H., Mataji A., Kafaki S., 2014. Oak forest decline zonation using AHP model and GIS technique in Zagros forests of Ilam province. Journal of Biodiversity and Environmental Sciences 4(3): 141-150.

Alesheikh A.A., Mehri S., 2019. Modeling oak decline using artificial neural networks (in Persian). Scientific-Research 
Quarterly of Geographical Data (SEPEHR) 28(110): 65-76. DOI 10.22131/SEPEHR.2019.36612.

Amir Ahmadi B., Zolfaghari R., Mirzaei M.R., 2015. Relation between Dieback of Quercus brantii Lindl. trees with ecological and Sylvicultural factors, (Study Area: Dena Protected Area) (in Persian). Ecology of Iranian Forests 3(6): 19-27.

Attarod P., Sadeghi S.M.M., Pypker T.G., Bayramzadeh V., 2017. Oak trees decline; a sign of climate variability impacts in the west of Iran. Caspian Journal of Environmental Sciences 15(4): 373-384.

Conte A.L., Di Pietro R., Iamonico D., Di Marzio P., Cillis G., Lucia D., Fortini P., 2019. Oak decline in the Mediterranean basin: A study case from the southern Apennines (Italy). Plant Sociology 56(2), 69-80. DOI 10.7338/ pls2019562/05.

Costa A., Pereira H., Madeira M., 2010. Analysis of spatial patterns of oak decline in cork oak woodlands in Mediterranean conditions. Annals of Forest Science 67(2): 204. DOI $10.1051 /$ forest $/ 2009097$.

Eckhardt L.G., Menard R.D., 2008. Topographic features associated with loblolly pine decline in central Alabama. Forest Ecology and Management 255(5-6): 735-1739. DOI 10.1016/j.foreco.2007.11.036.

Ghadirian O., Hemami M.R., Soffianian A., Pourmanafi S., Malekian M., 2018. The Zoning of Lorestan Province's forests decline risk using logistic regression model (in Persian). Journal of Animal Environment 10(3): 495-502.

Ghanbari Motlagh M., Amraei B., Halimi M., 2020. Evaluating the hazardous potential of the dieback of the $\mathrm{Za}-$ gros Oak forests using the multi-criteria decision-making methods. Arabian Journal of Geosciences 13: 995. DOI 10.1007/s12517-020-05992-6.

Gonzalez Alonso C., Johansson T., 2008. Analysis of the oak decline in Spain, La Seca, Bachelor thesis in forest management. Swedish University of Agricultural Scciences, SLU Uppsala: 76.

Goodarzi M., Pourhashemi M., Azizi Z., 2019. Investigation on Zagros forests cover changes under the recent droughts using satellite imagery. Journal of Forest Science 65(1): 9-17.

Greenwood D.L., Weisberg P.J., 2008. Density-dependent tree mortality in pinyon-juniper woodlands. Forest Ecology and Management 255(7): 2129-2137.

Hamzehpour M., Kia-daliri H., Bordbar K., 2011. Preliminary study of manna oak (Quercus brantii Lindl.) tree decline in Dashte-Barm of Kazeroon, Fars province (in Persian). Iranian Journal of Forest and Poplar Research 19(2): 352-363.

Hosseini A., Hosseini S.M., Calderón J.C.L., 2017. Site factors and stand conditions associated with Persian oak decline in Zagros mountain forests. Forest Systems 26(3): e014.

Hosseini A., Hosseini S.M., Linares J.C., 2019. Linking morphological and ecophysiological leaf traits to canopy dieback in Persian oak trees from central Zagros. Journal of Forestry Research 30(5): 1755-1764. DOI 10.1007/s11676018-0805-4.

Ilam Department [Ilam Department of Natural Resources and Watershed Management Report]. 2013. Report of Forest, Rangeland and Watershed Management Unit (in Persian). Ilam: 273.

Jahanbazi Gojani H., Iranmanesh Y., Talebi M., 2020. Factors affecting the decline of Zagros forests and its management solutions (in Persian). Iranian Forests and Rangelands Research Institute, Agricultural and Natural Resources Re- search and Training Center of Chaharmahal and Bakhtiari Province, Shahrekord: pp. 19.

Jurskis V., 2005. Eucalypt decline in Australia, and a general concept of tree decline and dieback. Forest Ecology and Management 215(1-3): 1-20.

Kabrick J.M., Dey D.C., Jensen R.G., Wallendorf M., 2008. The role of environmental factors in oak decline and mortality in the Ozark Highlands. Forest Ecology and Management 255(5-6): 1409-1417.

Keča N., Koufakis I., Dietershagen J., Nowakowska J.A., Oszako T., 2016. European oak decline phenomenon in relation to climatic changes. Folia Forestalia Polonica 58(3): 170-177. DOI 10.1515/ffp-2016-0019.

Kooh Soltani S., Alesheikh A.A., Ghermezcheshmeh B., Mehri S., 2018. An evaluation of potential Oak decline Forest of the Zagros using GIS, RS, FAHP methods (in Persian). Iranian Journal of Ecohydrology 5(2): 713-725. DOI 10.22059/IJE.2018.225917.448.

Lee S., 2007. Application and verification of fuzzy algebraic operators to landslide susceptibility mapping. Environmental Geology 52: 615-623. DOI 10.1007/s00254-0060491-y.

Lewis S.M., Fitts G., Kelly M., Dale L., 2014. A fuzzy logic-based spatial suitability model for drought-tolerant switchgrass in the United States. Computers and Electronics in Agriculture 103: 39-47. DOI 10.1016/j.compag.2014.02.006.

Mahdavi A., Mirzaei J., Karami O., 2015b. The status of dead standing trees in Zagros forest (Case study: Bioreh Forests in Ilam Province) (in Persian). Journal of Forest Sustainable Development 1(4): 329-340.

Mahdavi A., Mirzaei Zadeh V., Niknezhad M., Karami, O., 2015a. Assessment and prediction of oak trees decline using logistic regression model (Case study: Bivareh forest, Malekshahi-Ilam) (in Persian). Iranian Journal of Forest and Range Protection Research 13(1): 20-33. DOI 10.22092/ ijfrpr.2015.102389.

Mohebbi Tafreshi G., Nakhaei M., Lak R., 2019. Land subsidence risk assessment using GIS fuzzy logic spatial modeling in Varamin aquifer, Iran. GeoJournal. DOI 10.1007/ s10708-019-10129-8.

Mozafari F., Karamshahi A., Heydari M., karami O., 2019. Mapping Dieback intensity distribution in Zagros Oak forests using geo-statistics and artificial neural network. Iranian Journal of Applied Ecology 8(3): 31-44.

Nowakowska J.A., Stocki M., Stocka N., Ślusarski S., Tkaczyk M., Caetano J.M., Tulik M., Hsiang T., Oszako T., 2020. Interactions between Phytophthora cactorum, Armillaria gallica and Betula pendula Roth. Seedlings Subjected to Defoliation. Forests 11(10): 1107. DOI 10.3390/f11101107.

Oszako T., 2004. Protection of forests against pest insects and diseases: European oak decline study case. Forest Research Institute,Warsaw (Poland): pp150. ISBN 83-87647-37-3.

Oszako T., Sikora K., Borys M., Kubiak K.A., Tkaczyk M., 2016. Phytophthora quercina infections in elevated CO2 concentrations. Folia Forestalia Polonica 58(3): 131-141.

Pourhashemi M., Jahanbazi Goujani H., Hoseinzade J., Bordbar S.K., Iranmanesh Y., Khodakarami Y., 2017. The history of oak decline in Zagros forests (in Persian). Journal of Iran Nature 2(1): 30-37. DOI 10.22092/irn.2017.109535.

Raines G.L., Sawatzky D.L., Bonham-Carter, G.F., 2010. New fuzzy logic tools in ArcGIS 10. ArcUser, Spring.

Rostamnia M., Akhoondzadeh Hanzaei M., 2016. Assessment of hazardous drought of ilam province forests us- 
ing landsat satellite images (in Persian). Journal of Geomatics Science and Technology 6(2): 131-144.

Sohar K., Helama S., Läänelaid A., Raisio J., Tuomenvirta H., 2014. Oak decline in a southern Finnish forest as affected by a drought sequence. Geochronometria 41(1): 92-103.

Touhami I., Chirino E., Aouinti H., El Khorchani A., Elaieb M.T., Khaldi A., Nasr Z., 2019. Decline and dieback of cork oak (Quercus suber L.) forests in the Mediterranean basin: A case study of Kroumirie, Northwest Tunisia. Journal of Forestry Research 1-17. DOI 10.1007/s11676019-00974-1.
Woodward S., Bodles W.J., Oszako T., 2005. Occurence of phytophthora species in European forests. Folia Forestalia Polonica Series A 47: 5-12.

Zadeh L.A., 1965. Fuzzy sets. Information and Control 8: 338353.

Zandebasiri M., Soosani J., Pourhashemi M., 2017. Evaluation of the crisis severity in forests of Kohgiluye and Boyerahmad province (Case study: Tang-e Solak) (in Persian). Iranian Journal of Forest and Poplar Research 24(4): 665-674.

Zandebasiri M., Vacik H., Etongo D., Dorfstetter Y., Soosani J., Pourhashemi M., 2019. Application of time-cost tradeoff model in forest management projects: The case of Oak decline project. Journal of Forest Science 65(12): 481-492. 